\title{
ANALISIS KEPUTUSAN PEMBELIAN HANDPHONE VIVO (Studi Kasus Konsumen Gadget Mart Pelaihari)
}

\author{
Siti Raesa Rizki P \\ Akhmad Samhudi \\ Email: samhudi59@gmail.com
}

Fakultas Ekonomi Universitas Islam Kalimantan MAB Banjarmasin

\begin{abstract}
This research is based on a theoretical framework, expert ideas, or the understanding of researchers based on their experience, then developed into problems and solutions that are proposed to obtain justification (Verification) in the form of emperical data support in the field.

This study aims to find out and analyze how much influence the variables of product quality, price and promotion on purchasing decisions on VIVO mobile phones.

The method used in this study is a quantitative method, with a population of 40 , a sample of 40 people and data analysis techniques with research instruments validity test, reliability test and using multiple linear regression.

The results of this study indicate that the Product Quality, Price and Promotion variables individually and together influence the VIVO Mobile Purchase Decision on the Pelaihari Mart Gadget. Meanwhile, based on the results of the F Test at the level of $\alpha$ of $5 \%$, it proves that all the independent variables have a significant effect on the dependent variables together (simultaneous). Adjusted determination (R2) is 0.505 or $50.5 \%$, this shows the amount of contribution given by all independent variables on the dependent variable.
\end{abstract}

Keywords: Product Quality, Price, Promotion, Purchace Decision 


\section{PENDAHULUAN}

Persaingan perusahaan yang semakin ketat, menuntut perusahaan untuk menerapkan standar kualitas pada produk yang dihasilkannya. hal ini terjadi karena kualitas suatu produk menentukan berhasil atau tidaknya produk tersebut menembus pasar. Perosalan yang kemudian muncul adalah apabila produk yang dihasilkan suatu perusahaan merupakan produk yang juga dihasilkan oleh perusahaan lain, sehingga hal ini menimbulkan kompetisi atau persaingan dari berbagai perusahaan-perusahaan yang ada. Perusahaan satu dengan perusahaan lain akan saling berkompetisi agar produk yang dihasilkan mempunyai kualitas yang paling baik diantara produk yang dihasilkan oleh perusahaan sejenis.

Pertumbuhan dan perkembangan ekonomi dewasa ini menyebabkan persaingan bisnis menjadi semakin ketat. Tidak sedikit perusahaan-perusahaan baru bermunculan dengan menawarkan berbagai macam produk yang snagat bervariasi. Para produsen juga semakin kreatif dan inovatif dalam memasarkan produknya.

Handphone merupakan salah satu dari produk teknologi telekomunikasi seluler. Dengan kecanggihan teknologi saat ini, handphone tidak hanya sebagai alat komunikasi biasa, tetapi manusia juga dapat mengakses internet, menggunakan berbagai aplikasi chat, berfoto, dan juga saling mengirim data. Dampak yang ditimbulkan dari hanphone mungkin tidak disadari sama sekali Selain memudahkan dalam berkomunikasi sebagai dampak positif yang manusia dapatkan, terdapat pula dampak negative yang manusia dapatkan. terdapat pula dampak negative yang manusia dapatkan sebagai akibat menggunakan handphone.

Dengan semakin banyaknya jenis handphone yang ada maka perusahaan Handphone harus mampu bersaing sebagaimana menciptakan sebuah inovasi baru yang dapat memberikan kepuasan bagi pemakai handphone itu sendiri baik dari pengoperasiannya, kualitasnya, desainnya dan kelengkapan menunya 
sehingga dengan demikian konsumen dapat menentukan pilihannya. Dalam pengambilan keputusan tersebut, konsumen akan dipengaruhi oleh berbagai faktor, khususnya faktor kualitas produk, harga dan promosi (Fransisca Dewi Ritonga, 2012 : 14).

Disamping kualitas produk, perusahaan juga harus memperhatikan harga karena harga memiliki pengaruh terhadap perubahan permintaan suatu produk. Harga menurut Husain Umar (2015 : 32) adalah sejumlah nilai yang ditukarkan konsumen dengan manfaat dari memiliki atau menggunakan produk atau jasa yang nilainya ditetapkan oleh pembeli dan penjual melalui tawar menawar, atau ditetapkan oleh penjual untuk satu harga yang sama terhadap semua pembeli. Sesuai dengan hukum permintaan "semakin tinggi harga yang ditawarkan suatu produk, semakin rendah permintaan konsumen terhadap produk tersebut. Dan sebaliknya, semakin rendah harga yang ditawarkan suatu produk, semakin tinggi perminataan konsumen terhadap produk tersebut". Oleh karena itu, penetapan harga yang tepat perlu mendapatkan perhatian yang besar dari perusahaan.

Disamping kualitas produk dan harga, media promosi juga memperngaruhi keputusan pembeli. Media promosi yang sering digunakan untuk menyampaikan informasi tentang produk adalah media periklanan. Kotler (2009 : 202) menyatakan bahwa periklanan (advertising) adalah semua bentuk terbayar atas persentasi non pribadi dan promosi ide, barang atau jasa oleh sponsor yang jelas. Iklan akan memacu persaingan secara sehat, karena iklan akan memberikan informasi yang lebih lengkap tentang produk. Menurut N. Gregory Mankiw, sehingga keputusan pembelian terhadap produk menjadi semakin meningkat.

Salah satu smartphone Android yang paling digemari masyrakat saat ini adalah VIVO Smartphone. Sejak awal kemunculannya di dunia ponsel,. VIVO memang dikenal sebagai pabrikan yang seringkali menjual produk ponselnya dnegan harga cukup mahal. Sebagai produsen China, VIVO membukrikan bahwa kualitas ponselnya tak kalah dengan ponsel yang dibuat oleh pabrikan Jurnal Komunikasi Bisnis dan Manajemen 
ternama. Dan terbukti, walaupun ia masih terhitung pendatang baru, tetapi produk VIVO bisa bersaing dengan produk ponsel ternama lainnya.

Untuk menciptakan suatu produk dengan berbagai macam atribut yang sesuai dengan kebutuhan dan keinginan konsumen, maka operator seluler harus melakukan riset perilaku konsumen karena dalam perkembangan konsep pemasaran mutakhir, konsumen ditetapkan sebagai sentral perhatian. Para praktisi maupun akademisi berusaha mengkaji aspek-aspek konsumen dalam rangka mengembangkan strategi pemasaran yang diharapkan mampu meraih pangsa pasar yang tersedia.

Dengan adanya situasi tersebut maka permasalahan ini layak diteliti untuk mengetahui seberapa besar Pengaruh Kualitas Produk, Hrga dan Promosi terhadap keputusan pembelian handphone VIVO pada Gadget Mart Pelaihari sehingga dapat dilakukan perbaikan-perbaikan opleh perusahaan sebelum terjadi ketidakpuasan yang lebih tinggi dan merugikan perusahaan.

\section{METODE PENELITIAN}

Penelitian ni merupakan penelitian kuantitatif, apabila dilihat dari bentuk data yang diambil. Apabila dilihat dari tingkat eksplanasinya, penelitian ini merupakan penelitian asosiatif, yaitu suatu penelitian yang mencoba mencari hubungan antara variabel independen dengan variabel dependen, yaitu untuk mengetahui faktor-faktor yang mempengaruhi konsumen dalam keputusan pembelian Handphone VIVOdi Gadgetmart Pelaihari.

Data yang dikumpulkan dalam penelitian ini dilakukan melalui penyebaran kuesioner kepada Konsumen Handphone VIVO di GadgetmartPelaihari yang menjadi responden. Jumlah kuesioner yang dibagikan sebanyak 40 kuesioner. Analisis terhadap data hasil kuesioner yang diperoleh dari responden, merupakan sesuatu yang penting untuk mengetahui karakteristik responden yang dijadikan sampel dalam penelitian. 
(1)Jenis Kelamin

Tabel 1

Karateristik Responden berdasarkan jenis kelamin

\begin{tabular}{|c|c|c|c|}
\hline No & Jenis Kelamin & $\begin{array}{c}\text { Frekuensi } \\
\text { (orang) }\end{array}$ & $\begin{array}{c}\text { Persen } \\
(\%)\end{array}$ \\
\hline 1 & Laki-laki & 18 & $45 \%$ \\
\hline 2 & Perempuan & 22 & $55 \%$ \\
\hline \multicolumn{2}{|c|}{ Total Responden } & 40 & 100 \\
\hline
\end{tabular}

Sumber : Data primer diolah, 2018

(2) Umur

Tabel 2

Karakteristik Responden Berdasarkan Umur

\begin{tabular}{|c|c|c|c|}
\hline No & umur & $\begin{array}{c}\text { Frekuensi } \\
\text { (orang) }\end{array}$ & $\begin{array}{c}\text { Persen } \\
(\%)\end{array}$ \\
\hline 1 & Dibawah 20 tahun & 0 & $0 \%$ \\
\hline 2 & 20-30 tahun & 12 & $30 \%$ \\
\hline 3 & 31-40 tahun & 18 & $45 \%$ \\
\hline 4 & 40 tahun keatas & 10 & $25 \%$ \\
\hline \multicolumn{2}{|r|}{ Total Responden } & 40 & 100 \\
\hline
\end{tabular}

Sumber : Data primer diolah, 2018

(3) Status

Tabel 3

Karakteristik Responden Berdasarkan Status

\begin{tabular}{|c|c|c|c|}
\hline No & Status & $\begin{array}{c}\text { Frekuensi } \\
\text { (orang) }\end{array}$ & $\begin{array}{c}\text { Persen } \\
(\%)\end{array}$ \\
\hline 1 & Belum Kawin & 16 & $40 \%$ \\
\hline 2 & Kawin & 21 & $53 \%$ \\
\hline 3 & Janda/duda & 3 & $8 \%$ \\
\hline \multicolumn{2}{|c|}{ Total Responden } & 40 & 100 \\
\hline
\end{tabular}

Sumber : Data primer, diolah 2018 
(4) Pendidikan Terakhir

Tabel 4

Karakteristik Responden Berdasarkan Pendidikan Terakhir

\begin{tabular}{|c|c|c|c|}
\hline No & Pendidikan Terakhir & $\begin{array}{c}\text { Frekuensi } \\
\text { (orang) }\end{array}$ & $\begin{array}{c}\text { Persen } \\
(\%)\end{array}$ \\
\hline 1 & SD dan SLTP & 0 & $0 \%$ \\
\hline 2 & SLTA & 15 & $38 \%$ \\
\hline 3 & Diploma & 4 & $10 \%$ \\
\hline 4 & Sarjana & 21 & $53 \%$ \\
\hline 5 & Pasca Sarjana & 0 & $0 \%$ \\
\hline \multicolumn{2}{|c|}{ Total Responden } & 40 & 100 \\
\hline
\end{tabular}

Sumber : Data primer, diolah 2018

\section{HASIL DAN PEMBAHASAN}

\section{Analisis Deskriptif Variabel Penelitian}

Analisis deskriptif bertujuan untuk mendeskripsikan variabel-variabel penelitian melalui interprestasi distribusi frekuensi jawaban responden secara keseluruhan, baik dalam jumlah responden (orang), maupun dalam angka presentase terhadap item-nitenm variabel penelitian. Supriyanto dan Machfudz (2010), adapun frekuensi jawaban responden untuk jawaban pertanyaa vnariabel Kualitas Produk (X1), Harga (X2), Promosi (X3), dan Keputusan Pembelian (Y) di bawah ini :

(1) Variabel Kualitas Produk

Tabel 5

Distribusi Frekuensi Item Variabel Kualitas Produk (X1)

\begin{tabular}{|c|c|c|c|c|c|c|c|c|c|c|}
\hline \multicolumn{10}{|c|}{ Jawaban Responden } \\
\hline \multirow{2}{*}{ Item } & 1 (STS) & $2(\mathrm{TS})$ & \multicolumn{2}{|c|}{$3(\mathrm{~N})$} & \multicolumn{2}{|c|}{$4(\mathrm{~S})$} & \multicolumn{2}{c|}{$15(\mathrm{SS})$} \\
\cline { 2 - 12 } & $\mathrm{F}$ & $\%$ & $\mathrm{~F}$ & $\%$ & $\mathrm{~F}$ & $\%$ & $\mathrm{~F}$ & $\%$ & $\mathrm{~F}$ & $\%$ \\
\hline X1.1 & 1 & 2,5 & 5 & 12,5 & 2 & 5 & 7 & 17,5 & 25 & 62,5 \\
\hline X1.2 & 1 & 2,5 & 4 & 10 & 2 & 5 & 7 & 17,5 & 26 & 65 \\
\hline X1.3 & 0 & 0 & 2 & 12,5 & 2 & 5 & 8 & 20 & 25 & 62,5 \\
\hline X1.4 & 0 & 0 & 3 & 7,5 & 5 & 12,5 & 16 & 40 & 16 & 40 \\
\hline X1.5 & 1 & 2,5 & 3 & 7,5 & 5 & 12,5 & 6 & 15 & 25 & 62,5 \\
\hline
\end{tabular}


Dari tabel di atas dapat dijelaskan dari variabel Kualitas Produk (X1) pada item pertanyaan X1.1 dari 40 (empat puluh) orang responden yaitu Konsumen Handphone VIVO Gadget Mart Pelaihari jawaban dominan adalah menjawab sangat setuju sebanyak 25 orang $62,5 \%$.

Pada item pertanyaan X1.2 dari 40 (empat puluh) orang responden yaitu Konsumen Hanphonen VIBO Gadget Mart Pelaihari jawaban dominan responden adalah menjawab sangat setuju sebanyak 26 orang $65 \%$.

Pada item pertanyaan X1.3 dari $4{ }^{\prime} 8$ npat puluh) orang responden yaitu Konsumen Handphone VIVO Gadget Mart Pelaihari jawaban dominan responden adalah menjawab setuju sebanyak n25 nonrag $62,5 \%$.

Pada item pertanyaa X1.4 dari 40 (empat puluh) orang responden yaitu Kosumen Responden VIVO Gadget Mart Pelaihari jawaban dominan responden adalah menjawab setuju dan sangat setuju sebanyak 16 orang $40 \%$.

Pada item pertanyaan X1.5 dari 40 (empat puluh) orang responden yaitu Konsumen Handphone VIVo Gadget Mart Pelaihari jawaban dominan responden adalah menjawab setuju sebanyak 25 orang $62,5 \%$.

(2) Variabel Harga

Tabel 6

Distribusi Frekuensi Item Harga $\left(\mathrm{X}_{2}\right)$

\begin{tabular}{|c|c|c|c|c|c|c|c|c|c|c|}
\hline \multicolumn{10}{|c|}{ Jawaban Responden } \\
\hline \multirow{2}{*}{ Item } & 1 (STS) & 2 (TS) & \multicolumn{2}{|c|}{$3(\mathrm{~N})$} & $4(\mathrm{~S})$ & \multicolumn{2}{|c|}{15 (SS) } \\
\cline { 2 - 12 } & $\mathrm{F}$ & $\%$ & $\mathrm{~F}$ & $\%$ & $\mathrm{~F}$ & $\%$ & $\mathrm{~F}$ & $\%$ & $\mathrm{~F}$ & $\%$ \\
\hline X2.1 & 2 & 5 & 1 & 2,5 & 6 & 15 & 18 & 45 & 13 & 32,5 \\
\hline X2.2 & 2 & 5 & 1 & 2,5 & 3 & 7,5 & 8 & 20 & 26 & 65 \\
\hline X2.3 & 25 & 5 & 3 & 7,5 & 2 & 5 & 11 & 27,5 & 22 & 55 \\
\hline
\end{tabular}

Dari tabel 6 di atas dapat dijelaskan dari variabel Harga (X2) pada item pertanyaan X2.1 dari 40 (empat puluh) orang responden yaitu Konsumen 
Handphone VIVO Gadget Mart Pelaihari jawaban dominan adalah menjawab setuju sebanyak 18 orang $45 \%$.

Pada item pertanyaan X2.2 dari 40 (empat puluh) orang responden yaitu Konsumen Handphone VIVO Gadget Mart Pelaihari jawaban dominan adalah menjawab setuju sebanyak 18 orang $65 \%$.

Pada item pertanyaan X2.3 dari 40 (empat puluh) orang responden yaitu Konsumen Handphone VIVO Gadget Mart Pelaihari jawaban dominan adalah menjawab setuju sebanyak 22 orang $55 \%$.

(3) Variabel Promosi

\section{Tabel 7}

Distribusi Frekuensi Item Variabel Promosi (X3)

\begin{tabular}{|c|c|c|c|c|c|c|c|c|c|c|}
\hline \multicolumn{10}{|c|}{ Jawaban Responden } \\
\hline \multirow{2}{*}{ Item } & 1 (STS) & \multicolumn{2}{c|}{2 (TS) } & \multicolumn{2}{|c|}{$3(\mathrm{~N})$} & \multicolumn{2}{|c|}{4 (S) } & \multicolumn{2}{c|}{15 (SS) } \\
\cline { 2 - 12 } & F & $\%$ & F & $\%$ & F & $\%$ & F & $\%$ & F & $\%$ \\
\hline X3.1 & 2 & 5 & 1 & 2,5 & 2 & 5 & 16 & 40 & 19 & 47,5 \\
\hline X3.2 & 1 & 2,5 & 1 & 2,5 & 4 & 10 & 15 & 37,5 & 19 & 47,5 \\
\hline X3.3 & 1 & 2,5 & 1 & 2,5 & 3 & 7,5 & 16 & 40 & 19 & 4,75 \\
\hline
\end{tabular}

Dari tabel 7 di atas dapat dijelaskan dari variabel Promosi (X3) pada item pertanyaan X3.1 dari 40 (empat puluh) orang responden yaitu Konsumen Handphone VIVO Gadget Mart Pelaihari jawaban dominan adalah menjawab sangat setuju sebanyak 19 orang $47,5 \%$.

Pada item pertanyaan X3.2 dari 40 (empat puluh) orang responden yaitu Konsumen Handphone VIVO Gadget Mart Pelaihari jawaban dominan adalah menjawab sangat setuju sebanyak 19 orang $47,5 \%$.

Pada item pertanyaan X3.3 dari 40 (empat puluh) orang responden yaitu Konsumen Handphone VIVO Gadget Mart Pelaihari jawaban dominan adalah menjawab sangat setuju sebanyak 19 orang $47,5 \%$.

(4) Variabel Keputusan Konsumen 
Tabel 8

\section{Distribusi Frekuensi Item Variabel Keputusan Pembelian (Y)}

\begin{tabular}{|c|c|c|c|c|c|c|c|c|c|c|}
\hline \multicolumn{10}{|c|}{ Jawaban Responden } \\
\hline \multirow{2}{*}{ Item } & 1 (STS) & 2 (TS) & \multicolumn{2}{|c|}{$3(\mathrm{~N})$} & \multicolumn{2}{|c|}{$4(\mathrm{~S})$} & \multicolumn{2}{c|}{$15(\mathrm{SS})$} \\
\cline { 2 - 12 } & $\mathrm{F}$ & $\%$ & $\mathrm{~F}$ & $\%$ & $\mathrm{~F}$ & $\%$ & $\mathrm{~F}$ & $\%$ & $\mathrm{~F}$ & $\%$ \\
\hline Y.1 & 0 & 0 & 5 & 12,5 & 7 & 17,5 & 20 & 50 & 8 & 20 \\
\hline Y.2 & 0 & 0 & 2 & 5 & 11 & 27,5 & 21 & 52,5 & 6 & 15 \\
\hline Y.3 & 0 & 0 & 3 & 7,5 & 8 & 20 & 24 & 60 & 5 & 12,5 \\
\hline
\end{tabular}

Dari tabel 8 di atas dapat dijelaskan dari variabel Keputusan Pembelian (Y) pada item pertanyaan Y.1 dari 40 (empat puluh) orang responden yaitu Konsumen Handphone VIVO Gadget Mart Pelaihari jawaban dominan adalah menjawab sangat setuju sebanyak 20 orang $50 \%$.

Pada item pertanyaan Y.3 dari 40 (empat puluh) orang responden yaitu Konsumen Handphone VIVO Gadget Mart Pelaihari jawaban dominan adalah menjawab sangat setuju sebanyak 24 orang $60 \%$.

(5) Validitas dan Reliabilitas

Hasil uji validalitas dan reliabilitas instrument penelitian ini dapat dilihat pada tabel 9 di bawah ini:

Tabel 9

Rekapitulasi Hasil Uji Validitas Instrumen Penelitian

\begin{tabular}{|c|c|c|c|c|c|c|c|}
\hline Variabel & Item & $\mathrm{R}$ & $r_{\text {syarat }}$ & $\begin{array}{c}\text { Keteranga } \\
\mathrm{n}\end{array}$ & $\alpha$ & $\alpha_{\text {syarat }}$ & $\begin{array}{c}\text { Keteranga } \\
n\end{array}$ \\
\hline \multirow{5}{*}{$\begin{array}{l}\text { Kualitas } \\
\text { Produk } \\
\qquad(\mathrm{XI})\end{array}$} & XI.1 & 0,958 & 0,3 & Valid & \multirow{5}{*}{0,967} & \multirow{5}{*}{0,6} & \multirow{5}{*}{ Reliabel } \\
\hline & XI.2 & 0,968 & 0,3 & Valid & & & \\
\hline & XI.3 & 0,975 & 0,3 & Valid & & & \\
\hline & XI.4 & 0,839 & 0,3 & Valid & & & \\
\hline & XI.5 & 0,956 & 0,3 & Valid & & & \\
\hline \multirow{3}{*}{$\begin{array}{l}\text { Harga } \\
(X 2)\end{array}$} & $\mathrm{X} 2.1$ & 0,945 & 0,3 & Valid & \multirow{3}{*}{0,958} & \multirow{3}{*}{0,6} & \multirow{3}{*}{ Reliabel } \\
\hline & $X 2.2$ & 0,968 & 0,3 & Valid & & & \\
\hline & $\mathrm{X} 2.3$ & 0,970 & 0,3 & Valid & & & \\
\hline Promosi & X3.1 & 0,979 & 0,3 & Valid & 0,984 & 0,6 & Reliabel \\
\hline
\end{tabular}




\begin{tabular}{|c|c|c|c|c|c|c|c|}
\hline$(\mathrm{X})$ & $\mathrm{X} 3.2$ & 0,987 & 0,3 & Valid & & & \\
& $\mathrm{X} 3.35$ & 0,993 & 0,3 & Valid & & & \\
\hline Keputusan & Y.1 & 0,878 & 0,3 & Valid & & & \\
Konsumen & Y.2 & 0,884 & 0,3 & Valid & 0,866 & 0,6 & Reliabel \\
$(\mathrm{Y})$ & $\mathrm{Y} .3$ & 0,915 & 0,3 & Valid & & & \\
\hline
\end{tabular}

Berdasarkan tabel 9 diatas maka menunjukkan bahwa semua item pertanyaan pada variabel independent dan dependent memiliki nilai korelasi lebih besar dari $\mathrm{r}_{\text {syarat, }}$ instrument penelitian dapat dikatakan valid apabila koefisien korelasinya > dari 0,3 sugiyono dalam Supriyanto dan Machfudz (2008:296) dapat disimpulkan bahwa semua item pertanyaan adalah valid.

Uji Relibilitas dilakukan dengan tujuan menguji sejauh mana alat pengukur dapat diandalkan atau dipercaya. Dalam penelitian ini nilai realibilitas suatu instrument diterima jika memiliki Alpha Cronbach minimal 0,6. Arikunto dalam Supriyanto dan Machfudz (2014:296), maka dapat disimpulkan bahwa semua item pertanyaan adalah reliabel (dapat diandalkan atau dipercaya).

\section{Pembahasan}

\section{(1) Uji Hipotesis I : uji t secara parsial}

Melalui pengujian ini akan dapat diketahui apakah variabel yang tediri dari kualitas produk (X1), Harga (X2) Promosi (X3) berpengaruh parsial terhadap keputusan pembelian (Y) Handphone VIVO di Gadgetmart Pelaihari, yaitu dengan cara membandingkan nilai thitung dengan tabel, pada taraf signifikansi (taraf kepercayaan) $5 \%$ dan rumus derajat bebas/degree of freedom, $\mathrm{df}=\mathrm{n}-\mathrm{K}-1=40-4$ -1 = 35 maka didapat nilai tabel maka pengaruhnya signifikan. Selain itu juga dapat dilihat besarnya pergaruh masing-masing variabel bebas terhadap variabel terikatnya. 
Tabel 10

Nilai t hitung

\begin{tabular}{|c|c|c|c|c|c|}
\hline Varibel bebas & t hitung & Sig. & $\begin{array}{c}\mathrm{t} \text { tabel } \\
(\mathrm{df}: 35)\end{array}$ & Keterangan & $\begin{array}{c}\text { Signifikan atau } \\
\text { tidak signifikan }\end{array}$ \\
\hline XI Kualitas Produk & 2,731 & 0,010 & 2,030 & $\mathrm{t}$ hitung $>\mathrm{t}$ tabel & Signifikan \\
\hline X2 Harga Promosi & 2,450 & 0,019 & 2,030 & $\mathrm{t}$ hitung $>\mathrm{t}$ tabel & Signifikan \\
\hline X3 Promosi & 2,788 & 0,008 & 2.030 & $\mathrm{t}$ hitung $>\mathrm{t}$ tabel & Signifikan \\
\hline
\end{tabular}

Berdasarkan tabel 10 dapat dilihat pengaruh variabel kualitas produk (X1) terhadap keputusan pembelian (Y). Hal ini dapat dilhat dari tabel 5.2 dimana thitung $(2,731)>$ tabel $(2,030)$, sehingga dapat disimpulkan bahwa parsial kualitas produk (X1) berpengaruh signifikan secara sendiri - sendiri atau parsial terhadap keputusan pembelian (Y) Handphone VIVO di Gadgetmart Pelaihari.

Pengaruh variabel harga (X2) terhadap keputusan pembelian (Y), Harga (X2) berpengaruh signifikan secara parsial terhadap keputusan pembelian (Y). Hal ini dapat dilihat dari tabel5.2 dimana thitug $(2,450)>$ tabel $(2,030)$, sehingga dapat disimpulkan bahwa parsial kualitas produk (X1) berpengaruh signifikan secara sendiri-sendiri atau parsial keputusan pembelian (Y) HandphoneVIVO di GadgetmartPelaihari.

Pengaruh variabel Promosi (X3) berpengaruh signifikan secara parsial terhadap keputusan pembelian (Y). Hal ini dapat dilihat dari tabel 5.2 dimana thitung $(2,788)>$ tabel $(2,030)$, sehingga dapat disimpulkan bahwa parsial promosi (X3) berpengaruh signifikan secara sendiri-sendiri atau parsial terhadap keputusan pembelian (Y) HandphoneVIVO di Gadgetmart Pelaihari, dengan demikian hipotesis pertama yang mengatakan terdapat pengaruh secara parsial antara kualitas produk, harga dan promosi berpengaruh terhadap keputusan pembelian Handphone VIVO di Gadgetmart Pelaihari adalah benar atau teruji. 


\section{(2) Uji Hipotesis II : Uji F secara simultan}

Uji ini digunakan dengan tujuan untuk membuktikan apakah variabel bebas berpengaruh secara bersama-sama terhadap variabel terikat. Dalam menjawab hipotesis yang telah diajukan pada awal penelitian, menggunakan alat bantu analisis software SPSS versi 21.00. Dari hasil perhitungan melalui SPSS menunjukkan Fhitung sebesar 12,224 dan $F_{\text {tabel }}$ dengan menggunakan tingkat signifikansi (taraf kepercayaan) 5\% dan rumus derajat bebas/degree of freedom, $\mathrm{df}$ $1=-1=4-1=3$ dan df $2=\mathrm{n}-\mathrm{k}=40-3=37$ maka didapat nilai $\mathrm{F}_{\text {tabel }}$ Sebesar 2,860. Ini menyatakan bahwa Fhitung $(12,224)>F_{\text {tabel }}(2,860)$ sehingga hipotesis kedua yang mengatakan terdapat pengaruh secara simultan antara $\mathrm{k}$ produk, harga dan promosi berpengaruh terhadap keputusan pem Handphone VIVO di Gadgetmart Pelaihari dapat diterima atau teruji.

\section{KESIMPULAN DAN SARAN}

\section{Kesimpulan}

Penelitian ini bertujuan untuk menguji pengaruh kualitas produk, harga dan Promosi terhadap keputusan pembelian Handphone VIVO pada GadgetmartPelaihari, berdasarkan hasil analisis data dan pembahasan yang telah dilakukan, maka dapat ditarik kesimpulan :

1) Variabel kualitas produk, harga dan promosi berpengaruh signifikan secara parsial terhadap keputusan pembelian handphone VIVO pada Gadgetmart Pelaihari.

2) Variabel kualitas produk, harga dan promosi berpengaruh signifikan secara simultan terhadap keputusan pembelian handphone VIVO pada Gadgetmart Pelaihari.

\section{Saran-saran}

1) Hasil penelitian yang menunjukkan bahwa variabel kualitas produk merupakan variabel yang berpengaruh signifikan terhadap keputusan pembelian handphone Jurnal Komunikasi Bisnis dan Manajemen 
VIVO, untuk itu kedepannya spesifikasi keunggulan dan kelemahan produk Handphone VIVO agar konsumen dapat memutuskan pembelian dengan cepat karena telah mengetahui semua kualitas produk yang dimiliki Handphone VIVO.

2) Hasil Penelitian menunjukkan pengaruh variabel kualitas produk, harga dan promosi terhadap keputusan pembelian Handphone VIVO pada Gadgetmart Pelaihari sebesar 50,5\% untuk itu bagi peneliti selanjutnya hendaknya lebih mengembangkan lagi variabel lain yang mempengaruhi Keputusan pembelian Handphone VIVO karena 49,5\% dari hasil penelitian dijelaskan oleh sebab lain diluar dari penelitian ini.

\section{DAFTAR PUSTAKA}

Bulhari Alma, 2004 Manajemen Pemasaran dan Pemesanan Jasa, Alfabeta Bandung

Fendy Tjiptono, 2005, Strategi pemasaran andi Offset, Edisi Kedua Yogyakarta

Kotler \& Amstrong 2009, Prinsip-prinsip pemasaran jiild I, edisi kedelapan, Jakarta, Erlangga

Griffin, recky W, 2006, Bisnis edisi kedelapan, Jakarta, PT Gelora Aksara Pratama Kotler dan Keller, 2016, Marketing Management, Global Marketing, England; Pearson Education, Inc

Tjiptono (2012) Pemasaran Strategi, Yogyakarta, CV Andi Offset

Husein Umari, 2015 Metodologi Penelitian, Aplikasi dalam pemasaran gramedia pustaka utama, Jakarta

Sugiono, 2014, Metode Penelitian Manajemen, Bandung, Alfabeta

Rintongi, Fransilia Dewi, 2012, Pengaruh faktor-faktor psikologi terhadap pengambilan keputusan, Skripsi Universitas Sumatera Utara

Sugiono, Metodelogi Penelitian Bisnis, Alfabeta, Bandung, 2008

Mankiw, N Gregory (2003) Teori Makro ekonomi edisi kelima, terjemahan Jakarta Penerbit Erlangga 